\title{
Interventions to improve adherence in children with asthma: A systematic review
}

\author{
Christina Pearce ${ }^{1}$, Amy Chan ${ }^{1}$, Tracy Jackson ${ }^{2}$, Louise Fleming ${ }^{3}$, Holly Foot ${ }^{4}$, Andrew \\ Bush $^{5}$, and Robert Horne ${ }^{1}$ \\ ${ }^{1}$ University College London \\ ${ }^{2}$ The University of Edinburgh \\ ${ }^{3}$ Royal Brompton and Harefield NHS Foundation Trust \\ ${ }^{4}$ The University of Auckland \\ ${ }^{5}$ Imperial College London
}

October 5, 2021

\begin{abstract}
Introduction: Non-adherence to inhaled corticosteroids (ICS) in children with asthma leads to significant morbidity and mortality. Few interventions to improve adherence have been effective and little is known about what contributes to intervention effectiveness. This systematic review summarises the efficacy of these interventions and the characteristics of effective interventions to inform future studies aiming to improve adherence to ICS in children with asthma. Methods: PubMed, Embase, PsychINFO, Medline, Web of Science, and International Pharmaceutical Abstracts were systematically searched on the 3rd of October 2020 for randomised control trials measuring adherence to ICS in children with asthma. A narrative synthesis was conducted focusing on intervention efficacy and study reliability. Intervention content was coded based on the NICE guidelines for medicines adherence (The Perceptions and Practicalities Approach, PAPA) and Behaviour Change Techniques (BCT), to determine the effective aspects of the intervention. Results: Of 240 studies identified, 25 were eligible for inclusion. Thirteen of the twenty-five studies were categorised as being highly reliable. Nine of the thirteen studies were effective at increasing adherence and six of those met the criteria for a PAPA intervention. Conclusion: Adherence interventions in children with asthma have mixed effectiveness. Effective studies tended to be of higher quality, were tailored to individuals perceptual and practical adherence barriers, and used multiple BCTs. However, due to the small number of included studies and varying study design quality, conclusions drawn here are preliminary. Future research is needed to test a PAPA-based intervention with a rigorous study design as outlined in this review
\end{abstract}

\section{Interventions to improve adherence in children with asthma:}

\section{A systematic review}

Christina Joanne Pearce ${ }^{1,2}$, Amy Hai Yan Chan ${ }^{1,2,5}$, Tracy Jackson ${ }^{2}$, Louise Fleming ${ }^{2,3,4}$, Holly Foot ${ }^{5}$, Andy Bush ${ }^{2,3,4}$ and Rob Horne ${ }^{1,2,}$

Affiliations: ${ }^{1}$ School of Pharmacy, Department of Practice and Policy, University College London, London, Greater London, United Kingdom, ${ }^{2}$ Asthma UK Centre for Applied Research, ${ }^{3}$ Paediatric Respiratory Medicine, Royal Brompton Hospital, London, Greater London, United Kingdom, SW3 6NP, ${ }^{4}$ National Heart and Lung Institute, Imperial College London, London, Greater London, United Kingdom, SW7 2AZ, ${ }^{5}$ School of Pharmacy, The University of Auckland, Auckland, New Zealand. 
Corresponding author: Christina Joanne Pearce, UCL School of Pharmacy, Research department of Practice and Policy, BMA/Tavistock House, Mezzanine Floor, BMA House, Tavistock Square, London WC1H 9JP, United Kingdom. Email: christina.pearce.15@ucl.ac.uk

Take home message: Interventions to increase adherence to ICS can be effective in children with asthma, but more rigorous intervention methods are needed. Patients' beliefs about ICS and their ability to adhere should be targeted in future patient-tailored interventions.

Key words: Adherence; diagnosis; asthma; intervention; inhaled corticosteroids; systematic review

\begin{abstract}
Introduction: Non-adherence to inhaled corticosteroids (ICS) in children with asthma leads to significant morbidity and mortality. Few interventions to improve adherence have been effective and little is known about what contributes to intervention effectiveness. This systematic review summarises the efficacy of these interventions and the characteristics of effective interventions to inform future studies aiming to improve adherence to ICS in children with asthma.

Methods: PubMed, Embase, PsychINFO, Medline, Web of Science, and International Pharmaceutical Abstracts were systematically searched on the $3^{\text {rd }}$ of October 2020 for randomised control trials measuring adherence to ICS in children with asthma. A narrative synthesis was conducted focusing on intervention efficacy and study reliability. Intervention content was coded based on the NICE guidelines for medicines adherence (The Perceptions and Practicalities Approach, PAPA) and Behaviour Change Techniques (BCT), to determine the effective aspects of the intervention.

Results: Of 240 studies identified, 25 were eligible for inclusion. Thirteen of the twenty-five studies were categorised as being highly reliable. Nine of the thirteen studies were effective at increasing adherence and six of those met the criteria for a PAPA intervention.

Conclusion: Adherence interventions in children with asthma have mixed effectiveness. Effective studies tended to be of higher quality, were tailored to individuals perceptual and practical adherence barriers, and used multiple BCTs. However, due to the small number of included studies and varying study design quality, conclusions drawn here are preliminary. Future research is needed to test a PAPA-based intervention with a rigorous study design as outlined in this review.
\end{abstract}

\title{
Introduction
}

Asthma is the most common chronic non-communicable disease in children worldwide ${ }^{1}$. Asthma prevalence is higher in children in Europe (8.9\%), compared to the rest of the world $(7.2 \%)^{2}$ but varies between countries ${ }^{3}$. Most children with asthma achieve good disease control with maintenance low dose inhaled corticosteroids (ICS), which are effective at preventing most asthma hospitalisations and deaths ${ }^{4}$. However, some children remain poorly controlled despite being prescribed high-dose ICS treatment, often due to poor adherence. This contributes to suboptimal asthma control and severe attacks ${ }^{5 ; 6}$. Up to half of patients attending tertiary care paediatric asthma clinics are non-adherent (defined as taking less than $80 \%$ of their prescribed dose $)^{7}$.

The Global Initiate for Asthma (GINA) highlights that suboptimal use of asthma treatment is a patientspecific barrier that contributes to the burden of asthma ${ }^{8}$. Similarly, the UK National Review of Asthma Deaths reported that $67 \%$ of asthma deaths were avoidable, and one of the most important avoidable factors was low ICS adherence in the month and/or year before death ${ }^{9}$.

Many interventions have been developed to address the issue of poor ICS adherence in children. A metaanalysis in adults and children identified that interventions for improving adherence in asthma can be 
effective ${ }^{10}$. However, the meta-analysis did not examine the intervention characteristics e.g. content, channel of delivery and context of the intervention, which form the three components of behaviour change framework $\left(3 \mathrm{CBC}^{11}\right)$ in relation to intervention efficacy. It is important to be able to identify characteristics of effective interventions so that they may be applied in practice.

Moreover, the reliability of the diagnosis of asthma and the adherence measurement tool have not previously been used to identify high reliability interventions. If patients are diagnosed with asthma incorrectly, nonadherence to a treatment that is therefore unnecessary is logical. Similarly, if adherence is overestimated in studies using unreliable adherence measurements, then the conclusions drawn from the studies will also be inaccurate. By investigating these factors, the data presented in this review are likely to be more relevant to practice as they represent a rigorous test of the intervention.

The National Institute for Clinical Excellence (NICE) has developed guidelines intended to aid the design of adherence support for long term conditions at any stage of the life span ${ }^{12}$. The guidelines apply the Perceptions and Practicalities Approach (PAPA ${ }^{13}$ E-image 1). This approach recognises that adherence varies within the individual, over time and across treatments. Adherence/non-adherence is best understood in terms of the interaction between an individual and a particular treatment. It is a variable behaviour rather than a trait characteristic. The Perceptions and Practicalities Approach (PAPA) conceptualises adherence as including both intentional and unintentional non-adherence.

The application of the PAPA approach to adherence interventions has the following key features firstly, the need for a no-blame approach as patients are often reluctant to admit to non-adherence, or to concerns about the treatment, as they fear that this may be interpreted by the clinician as doubting their expertise. Hence, non-adherence and the reasons for it are often hidden. The second key feature is the need to tailor support to address both perceptions (e.g. beliefs about asthma and its treatment) and practicalities (e.g. clear instructions on inhaler technique, establishing a medication routine). Both perceptions and practicalities influence the patient's motivation and ability to start and continue taking the treatment. Indeed, research in asthma has shown beliefs about ICS are often important perceptual barriers to adherence, particularly doubts about the personal need for regular inhaler use particularly in the absence of symptoms and concerns about corticosteroids ${ }^{14 ;} 15$.

This systematic review aims to address these research gaps by 1 . Specifically examining adherence in children with asthma 2. Using quality indicators to identify those studies that may be more informative, and3. Examining the characteristics of adherence interventions to identify features that may be relevant to practice.

\section{Methods}

\section{Search Strategy}

PubMed, Embase, PsychINFO, Medline, Web of Science, and International Pharmaceutical Abstracts databases were searched systematically from the date of database inception until $3^{\text {rd }}$ October 2020 to identify relevant literature. MeSH, Emtree and truncated terms were used where applicable (E-table 1). Key search terms were: asthma, child, Intervention, adherence and randomized. All authors were contacted via email or, if not reachable via this route, by ResearchGate messaging for further details about the studies.

\section{Study selection}

Authors CP and TJ reviewed the abstracts, followed by the full texts against the inclusion/exclusion criteria. Where there were differing opinions a third, opinion was sought $(\mathrm{RH})$. Inclusion criteria were based on the Participant-Intervention-Comparison-Outcome-Study Design (PICOS) framework. Any interventions that focused on adherence to ICS with at least one outcome measure of adherence and used a randomised control trial (RCT) design were included. The comparison group was either usual treatment or basic education 
arms. Articles were included where the full text was written in English, and where the population of interest was patients aged 0-18 years old with a diagnosis of asthma. Although many preschool children with wheeze do not respond to $\mathrm{ICS}^{16}$, studies often recruit younger children and therefore this age-range was intended to avoid missing relevant articles. If they do not have the treatable trait of airway eosinophilia likely to respond to ICS ${ }^{17}$ this will be highlighted in the section regarding reliability of the criteria for asthma diagnosis. Studies were excluded if they did not meet the above criteria or if they were an RCT comparing two medications only, or where the majority of participants were not children (e.g. the mean age of participants was over 18 years or only adults were recruited).

\section{Data Extraction and Synthesis}

Following full-text review, CP and TJ extracted details of: study characteristics (setting, number of participants, diagnosis criteria, intervention and control descriptions and the outcome of interest); Effectiveness; Risk of Bias (RoB); and Behaviour change techniques (BCTs); target of the BCTs; relationship to PAPA.

Intervention Content

Intervention content were coded for PAPA as follows: Level 1 (intervention only targeted perceptions or only practicalities and not tailored); Level 2 (both perceptions and practicalities targeted but not tailored or only targeting one component (perceptions or practicalities) and tailored) and Level 3 (both perceptions and practicalities targeted and tailored to the individual).

Specific components within the intervention for changing adherence (Behaviour Change Techniques; BCTs) were also coded independently using BCT taxonomy V1 app ${ }^{18}$. Any differences in the selected BCTs were discussed until consensus was reached (Table 1).

Risk of Bias

RoB was assessed independently using the Cochrane Risk of Bias Handbook ${ }^{19}$ by CP, AC and HF using the Covidence platform (www.covidence.org) to record coding decisions and consensus discussions. The RoB score was based on the adherence outcome. Each study was scored across five domains: selection bias; performance and detection bias, attrition bias and reporting bias, and was scored as either low, high or unclear risk for each study. Authors were contacted for clarity when information relating to domains seemed unclear.

\section{Study Reliability}

To ascertain which interventions were truly effective, study reliability was considered. Although other validated tools have been used to assess quality such as the Grading of Recommendations, Assessment, Development and Evaluations (GRADE) tool ${ }^{20}$ the authors felt that there were several crossovers between risk of bias, the reliability scores, the 3CBC approach and in particular, the indirectness section of the GRADE tool and based on the aim of this review the reliability measurements would be more useful when considered with RoB. Both diagnosis and adherence measures can range from being subjective to objective, therefore considering the reliability of the approaches used is key for determining study reliability. Through multidisciplinary team discussions (including with respiratory physicians, pharmacists and a health psychologist) a coding hierarchy that considered the reliability of the asthma diagnosis and adherence measurement used was created and applied to the specific studies within this review (E-table 2).

Based on the RoB, the reliability of the asthma diagnosis, and the objectivity of the adherence measurement, the most reliable and least biased studies were used to ascertain what components constituted an effective intervention. Previous literature suggests that optimising the context, channel of delivery, and content of the intervention is important for intervention effectiveness ${ }^{11}$, and thus the $3 \mathrm{CBC}^{11}$ was also applied to this review.

Studies were summarised by a narrative synthesis. Meta-analysis was not conducted due to the wide study heterogeneity in terms of setting, asthma diagnosis criteria, and outcome measures used. The 
study protocol is published on PROSPERO (https://www.crd.york.ac.uk/prospero/\#searchadvanced) (ref: CRD42016029213).

\section{Results}

\section{Search Results}

The literature search retrieved 255 articles. An additional nine were identified from other sources. Twentytwo duplicate articles were removed before abstract screening. Based on abstract screening, 202 papers were excluded and a further 13 papers were excluded based on the full text. Main reasons for exclusion were: study design not an RCT; no usual care control group; medication adherence not included as a usable outcome; trial compared medications or was conducted in adults. Twenty-five studies were included in the narrative synthesis ${ }^{21-45}$; see full PRISMA diagram (Figure 1).

Figure 1: PRISMA flow diagram showing study selection

\section{Narrative Synthesis}

\section{Study characteristics}

Effect on adherence

Less than half of the interventions $(44 \%, 11 / 25)$ showed significant improvement in adherence in the intervention groups compared to the control groups ${ }^{23-25 ; 32-34 ; 36-38 ; 41 ; 44}$ (Table 2).

\section{Study Reliability}

Although half of the studies were reported as effective at increasing adherence the study reliability varied widely (Table 3). A wide range of criteria were used for the diagnosis of asthma and therefore the patient sample included in each study was heterogeneous. Where reported, most diagnoses were based on guidelines such as GINA, National Heart, Lung, and Blood Institute (NHLBI) $24 ; 25 ; 35$ or a physician diagnosis plus a prescription for ICS ${ }^{23 ; 26 ; 28-30 ; 37}(50 \%, 9 / 18)$. Just under half $(44 \%, 8 / 18)$ reported using an asthma diagnosis given by the emergency department physician $^{21 ; 32 ; 38}$, where patients asthma symptoms will have been directly observed by physicians, or by diagnosis from medical records $22 ; 27 ; 31 ; 34 ; 36$. Asthma diagnosis criteria was generally poorly reported.

Based on the coding hierarchy which considers the reliability of the asthma diagnosis (E-table 2), seven studies used reliable means to diagnose asthma in their participants ${ }^{21 ; 23 ; 24 ; 32 ; 36-38}$. Three studies used less reliable methods ${ }^{25 ; 34 ; 35}$ and a further seven used unreliable diagnostic methods ${ }^{22 ;}{ }^{26-31}$. In one study the method of diagnosis of asthma was unclear ${ }^{33}$.

Adherence measurement varied with studies using objective and subjective measures. Based on our coding hierarchy of objectivity of adherence measurements (E-table 2), most studies used more objective measurements ${ }^{23 ;} 24 ; 28 ; 31 ; 33 ; 34 ; 36 ; 37$ or both objective and subjective measures ${ }^{26} ; 27 ; 35$. Six used subjective measurements of adherence only $21 ; 22 ; 25 ; 30 ; 32 ; 38$ and for one study, the method of adherence measurement was unclear ${ }^{29}$. Based on the RoB, reliability of asthma diagnosis and objectivity of the adherence measurement within each study the reliability of the evidence can be summarised (Table 3).

\section{Risk of Bias}

Risk of bias within studies 


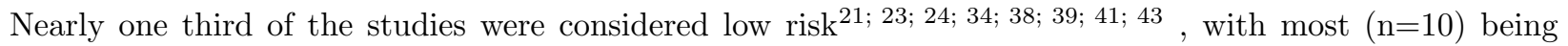
considered moderate risk $22 ; 26 ; 30 ; 32 ; 33 ; 35-37 ; 40 ; 44$. Six studies were considered high risk ${ }^{25 ; 27-29 ; 31 ; 42}$ (Table 3 and Figure 2).

Figure 2: Risk of Bias within and across studies

Risk of bias across studies

The main bias identified was performance bias. Overall, RoB was low for most studies in terms of selection bias (random sequence generation); detection bias (blinding of outcome assessment) and reporting bias (selective reporting bias). Section bias (allocation concealment) was often low or unclear and was generally poorly reported. Attrition bias (incomplete outcome data) was frequently unclear or high risk (Figure 2).

\section{Reliability of the evidence}

The most reliable studies (i.e. moderate or high reliability based on asthma diagnosis and adherence measurement criteria) and low/ moderate RoB are discussed in more detail below. Nine of the thirteen studies in this category were effective at increasing adherence ${ }^{23 ; 24 ; 32-34 ; 36-38 ; 41}$ and four were ineffective ${ }^{21 ; 26 ; 35 ; 39}$. The following section compares the nine effective studies with the four ineffective studies within this high reliability group. Of those studies which reported effectiveness for increasing adherence, only one study was not considered to be in the high reliability group.

Components of effective interventions

This section will summarise the findings of this systematic review based on the $3 \mathrm{CBC}$ framework ${ }^{11}$ in order to critically appraise the effectiveness of the components within the most reliable intervention study evidence.

\section{Context}

The eight effective studies were conducted in Brazil $^{24}$; Greece ${ }^{41} ;$ New Zealand ${ }^{23 ;} 32$; China ${ }^{44}$; the USA ${ }^{38}$;

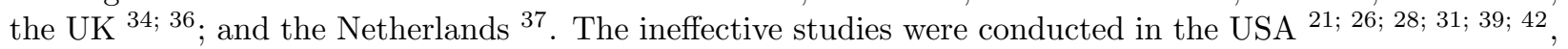
Taiwan $^{35}$, Brazil ${ }^{45}$, the Netherlands ${ }^{40}$ and Sweden ${ }^{43 ; 46}$. Effective studies took place in an emergency care setting ${ }^{23 ; 38}$; primary care ${ }^{24 ; 34}$; hospital outpatients ${ }^{33 ; 36 ; 37 ; 41 ; 44}$; and in the community $32 ; 44$. The ineffective studies took place in: emergency care ${ }^{21 ; 39}$, in the community ${ }^{26 ; 40}$, primary care ${ }^{42 ;} 43$ and in hospital outpatients $35 ; 43 ; 45$.

There are no data regarding whether or not the interventions used a no-blame approach ${ }^{11}$ but three of the high reliability effective studies were clearly tailored to the patient ${ }^{24 ; 32 ; 33 ; 41}$ compared with only one of the ineffective studies ${ }^{35}$.

\section{Channel of Delivery}

Seven of the high reliability effective studies used technology to deliver the intervention including using electronic monitoring devices (EMDs ${ }^{23 ; 33 ; 36 ; 37 ; 41}$ ), the telephone ${ }^{24}$, a patient and health-care provider $\operatorname{app}^{44}$ and a SMS-based system ${ }^{37}$. Seven of the ineffective studies used technology to deliver the intervention via an educational video ${ }^{42}$, website and monthly telephone calls ${ }^{26}$, SMS text reminder and tips (not personalised) ${ }^{39}$, a smartphone $\operatorname{app}^{40 ; 43}$ and via the internet alone ${ }^{35}$. Different health care practitioners were involved in the interventions. Effective studies involved Pharmacists ${ }^{23 ; 37}$, nurses $23 ; 24 ; 32 ; 33 ; 36 ; 41 ; 44$, specialist physicians ${ }^{32 ; 33 ; 36-38 ; 44}$, community health workers ${ }^{32}$ and researchers ${ }^{37}$. In one study (1/8), the only channel was a letter sent from the patients' GP ${ }^{34}$ to the parents of the child with asthma. The ineffective studies used limited contact with any health care practitioner ${ }^{21}$, pharmacist $^{40}$,nurse ${ }^{26 ; 35 ; 42 ; 45}$ and physician ${ }^{35 ; 42 ; 43}$.

\section{Content}

Summary of perceptions and practicalities targeted by adherence interventions 
Of the nine effective and highly reliable studies, six met the criteria for Level $3(67 \% ; 24 ; 32 ; 33 ; 36 ; 38 ; 41$ (Table 4 ). The three other effective and high reliability studies were categorised as Level 1 or Level 2 with one untailored intervention focusing practical and perceptual factors ${ }^{34}$, one focusing only on practical factors 23 and one targeting practicalities in a tailored way ${ }^{37}$. Of the highly reliable studies only four were not effective- two were categorised as Level $3^{26 ; 35}$, one was categorised as Level $2^{39}$ and one was categorised as Level $1^{21}$.

Only two effective studies were classified as low reliability and categorised as Level $3^{25 ; 44}$. The ineffective and low reliability studies were either classed as Level 1 (no tailoring) ${ }^{27 ; 42 ; 43}$, Level 2 perceptual only ${ }^{29 ;} 30$, or both but not tailored ${ }^{22}$ or Level $3^{28 ; 31 ; 40 ; 45}$. Therefore, only six studies using Level 3 PAPA were not effective $(6 / 25,24 \%)$, four of which were classed as low reliability studies. Overall, only 18\% (2/11) of high reliability studies using Level 3 of the PAPA did not result in effective studies.

\section{Summary of Behaviour Change Techniques used}

The most commonly used Behaviour Change techniques within effective and highly reliable study interventions were: Non-specific rewards ${ }^{33}$; Prompts/cues 23; 24; 33; 34; 36; 37; 39; 41; 44; Feedback and Monitoring 23; 33; 36-38; Pharmacological support (this often involved providing free medications in countries where medications were not free and providing a longer-term supply when the medications were free) $23 ; 24 ; 33 ; 34 ; 38$; Instruction on how to perform a behaviour ${ }^{32}, 33 ; 36 ; 38 ; 41$ and Information about antecedents ${ }^{32 ;} 41$. Relevant to the age of the participants, the BCTs most often targeted both parent and child with the aim (primary or secondary outcome) of improving the child's adherence to ICS. Only in one instance did the BCT pharmacological support target only the parent in the form of a letter to encourage the parent to pick-up the child's ICS prescription ${ }^{34}$. Four further studies specified that the interventions targeted the child specifically ${ }^{23}$ and these were often with older children $24 ; 28 ; 29$. For extracted examples of common behaviour change technique and the studies they were used in see Table 5. For full details of the behaviour change technique extraction for each included study see Table 1.

\section{Discussion}

\section{Summary of the Evidence}

This is the first review to summarise effective interventions to increase adherence in children with asthma, taking into account the reliability of the studies and the behaviour change framework and techniques used in a clinically meaningful way. Previous reviews of adherence interventions in adults and children have shown that only half of interventions are effective at increasing adherence ${ }^{10}$. Similarly, we found that only nearly half of the included studies $(11 / 25)$ were effective at significantly increasing adherence $23-25 ; 32-34 ; 36-38 ; 41 ; 44$. We then explored the crucial factors for an effective intervention to increase adherence.

Of the thirteen studies that were effective, nine were considered highly reliably $23 ; 24 ; 32-34 ; 36-38 ; 41$. By comparing the effective and reliable studies (9/25) (accurate asthma diagnosis, objective adherence measure and low/moderate RoB) to the unreliable or ineffective studies this review should inform the development of future interventions. In terms of context high reliability interventions carried out in the UK (2/25) and New Zealand $(2 / 25)$ were most likely to be effective. High reliability Interventions carried out in the USA were most often ineffective (6/25 versus $1 / 25$ that was effective). However, regarding healthcare context there were no differences between different healthcare settings such as primary or secondary care. Three of the four high reliability but ineffective studies were not tailored to the patient group $21 ; 39 ; 47$. This highlights the importance of tailoring as it has been well reported that tailoring is associated with more effective interventions ${ }^{12}$.

The findings of this review support the use of technology as a channel to deliver the adherence intervention including electronic monitoring devices for measuring adherence and patient and health-care provider apps and telephone calls. Healthcare practitioner type is not as important as face-to-face contact while providing 
digital interventions. This finding supports a previous recent review based on digital interventions in longterm conditions ${ }^{48}$. Those planning an adherence intervention should therefore consider the amount of contact alongside digital interventions as a key component to future effectiveness.

In terms of content, six out of the nine reliable effective interventions were coded as Level 3 PAPA $24 ; 32 ; 33 ; 36 ; 38 ; 41$. Three high reliability and effective studies did not meet the criteria for Level 3 PAPA 23; 34; 37. Overall, only two of the highly reliable studies based on Level 3 PAPA did not result in effective interventions ${ }^{26 ; 35}$. The two studies had moderate risk of bias and did not involved face-to-face contact with a healthcare professional.

PAPA is easy to apply when developing an intervention as it simply highlights the effective minimal ingredients for change in adherence ${ }^{49}$. This review found that currently developed interventions in this area largely neglect the role played by patient beliefs about asthma and ICS. Research shows that these are often important determinants of non-adherence in adults ${ }^{50 ; 51}$ and there is immerging evidence of relevance in children ${ }^{52}$ : in terms of parental ${ }^{53 ; 54}$ and adolescent beliefs ${ }^{14 ; 15}$. Patient's perceptions that are of particular importance are beliefs about their personal need for treatment (even in the absence of symptoms) and concerns about steroid safety. These issues are important because necessity and concern beliefs may be the drivers of adherence as they influence motivation to adhere to treatment ${ }^{55 ;} 56$.

The most common BCTs used in effective interventions were prompts/cues (e.g. reminders), feedback and monitoring; pharmacological support and instruction of how to perform a behaviour. Each BCT was found to be most effective as part of complex interventions when tailored to the patient. It is currently unknown how many and what combination of BCTs are likely to increase the effectiveness of an intervention. However, this review is the first to show that particular BCTs are important to consider when developing a tailored intervention for increasing adherence in children with asthma.

\section{Strengths and Limitations}

Due to the heterogeneity of the adherence outcomes, limited availability of raw data and a small number of eligible studies a meta-analysis was not possible within this review.

This systematic review focuses on adherence as an outcome as opposed to clinical health outcomes as unlike within the adult literature, few studies in paediatric asthma include both adherence and clinical outcomes. Focusing on adherence therefore allowed a greater number of studies to be synthesised. Ideally intervention studies should have an objective reliable clinical outcome as well as an adherence outcome to account for potential patient manipulation of the adherence measurement and for those patients that may have low adherence despite good control (likely over-medicated). However, unlike in some other conditions, adherence to ICS has been shown to be highly correlated with objective clinical outcomes ${ }^{57}$ and therefore the use of adherence as a primary focus for this review is a reasonable proxy.

Most of the interventions had a moderate RoB which was increased by the high level of performance bias which is common in behavioural interventions. This is due to the lack of ability to blind patients and personnel to the purpose of the study, however, many of the studies tried to counteract that using deception (where ethically permitted). This included objective electronic monitoring devices also for control groups and additional measurements to distract from the adherence data collection. The studies often had low selection bias (for random sequence generation); detection bias and reporting bias; However, attrition bias and allocation concealment was frequently unclear with modern recommended reporting guidelines such as CONSORT $^{58}$ not being followed. We recommend using objective methods of measuring adherence and also more than one method of measurement, and also for the diagnosis of asthma, alongside blinding to increase the reliability of future intervention findings.

One further limitation is not excluding interventions where the diagnosis of asthma reported was not rigorous, for example where primary care medical records were used to identify those with asthma despite no record of prescribing ICS or where a physician diagnosis was given without objective measurement of asthma ${ }^{59}$. Future intervention studies should ensure the children recruited have a reliable diagnosis of asthma and objective 
measurements of adherence so the true effectiveness of the interventions can be determined ${ }^{60}$. Therefore, this review considered the reliability of the evidence for both the diagnosis of asthma, the measurement of adherence and the risk of bias of the studies.

\section{Conclusions}

Adherence interventions in children with asthma have mixed effectiveness. Effective studies tended to be of higher quality, targeted both perceptual and practical adherence barriers in a tailored manner, and used a combination of BCTs. However, due to the small number of included studies and varying study design quality, conclusions drawn here are preliminary.

None of the studies have explicitly addressed ICS necessity and concern beliefs. This remains a potential area of investigation as a method for enhancing adherence. Future interventions could consider a closer use of the NICE guidelines including addressing patient's beliefs and the channel by which the intervention is delivered; the increasing use of EMD with feedback delivered in a no-blame collaborative consultation. Future research is needed to test a PAPA-based intervention with a rigorous study design as outlined in this review.

\section{Funding}

Funding by the Asthma UK Centre for Applied Research via a $\mathrm{PhD}$ studentship. RH is also funded by NIHR CLAHRC North Thames. AB is an NIHR Senior Investigator emeritus. LF is an Asthma UK Senior Clinical Fellow.

\section{References}

1. Asher I, Pearce N. 2014. Global burden of asthma among children. The International Journal of Tuberculosis and Lung Disease. 18(11):1269-1278.

2. Vos T, Abajobir AA, Abbafati C, Abbas KM, Abate KH, Abd-Allah F, Abdulle AM, Abebo TA, Abera SF, Aboyans V et al. 2017. Global, regional, and national incidence, prevalence, and years lived with disability for 328 diseases and injuries for 195 countries, 1990-2016: A systematic analysis for the global burden of disease study 2016. Lancet. 390(10100):1211-1259.

3. Lai CKW, Beasley R, Crane J, Foliaki S, Shah J, Weiland S, Grp IPTS. 2009. Global variation in the prevalence and severity of asthma symptoms: Phase three of the international study of asthma and allergies in childhood (isaac). Thorax. 64(6):476-483.

4. Suissa S, Ernst P. 2001. Inhaled corticosteroids: Impact on asthma morbidity and mortality. The Journal of allergy and clinical immunology. 107(6):937-944.

5. Williams LK, Peterson EL, Wells K, Ahmedani BK, Kumar R, Burchard EG, Chowdhry VK, Favro D, Lanfear DE, Pladevall M. 2011. Quantifying the proportion of severe asthma exacerbations attributable to inhaled corticosteroid nonadherence. The Journal of allergy and clinical immunology. 128(6):1185-1191 e1182.

6. Engelkes M, Janssens HM, de Jongste JC, Sturkenboom MCJM, Verhamme KMC. 2015. Medication adherence and the risk of severe asthma exacerbations: A systematic review. Eur Respir J. 45(2):396-407.

7. Bracken M, Fleming L, Hall P, Van Stiphout N, Bossley C, Biggart E, Wilson NM, Bush A. 2009. The importance of nurse-led home visits in the assessment of children with problematic asthma. Archives of Disease in Childhood. 94(10):780-784.

8. Masoli M, Fabian D, Holt S, Beasley R, Global Initiative for Asthma P. 2004. The global burden of asthma: Executive summary of the gina dissemination committee report. Allergy. 59(5):469-478. 
9. Levy M, Andrews R, Buckingham R, Evans H, Houston R, Puri N, Stewart K. 2014. Why asthma still kills national review of asthma deaths (nrad). Eur Respir J. 44.

10. Normansell R, Kew KM, Stovold E. 2017. Interventions to improve adherence to inhaled steroids for asthma. The Cochrane database of systematic reviews. 4:CD012226.

11. Horne R. 2012. Improving adherence with asthma therapies. In: Polosa R, Papale G, Holgate ST, editors. Advances in asthma management. London: Future Medicine. p. 132-142.

12. Nunes V, Neilson J, O'flynn N, Calvert N, Kuntze S, Smithson H, Benson J, Blair J, Bowser A, Clyne W et al. 2009. Clinical guidelines and evidence review for medicines adherence: Involving patients in decisions about prescribed medicines and supporting adherence. . London:.

13. Horne R, Weinman J, Barber N, Elliott R, Morgan M, Cribb A. 2005. Concordance, adherence and compliance in medicine taking: Report for the national co-ordinating centre for nhs service delivery and organisation $\mathrm{r} \& \mathrm{~d}$ (nccsdo). London.

14. De Simoni A, Horne R, Fleming L, Bush A, Griffiths C. 2017. What do adolescents with asthma really think about adherence to inhalers? Insights from a qualitative analysis of a uk online forum. BMJ Open. 7(6):e015245.

15. Pearce CJ, Chan A, Horne R, Fleming L, Bush A, Jamalzadeh A. 2018. "It's like trying to fit a piece into an already not working puzzle": Non adherence to inhaled corticosteroids in young people with problematic asthma: A qualitative study. Paper presented at: Int J Behav Med.

16. Fitzpatrick AM, Jackson DJ, Mauger DT, Boehmer SJ, Phipatanakul W, Sheehan WJ, Moy JN, Paul IM, Bacharier LB, Cabana MD et al. 2016. Individualized therapy for persistent asthma in young children. The Journal of allergy and clinical immunology. 138(6):1608-1618 e1612.

17. Pavord ID, Beasley R, Agusti A, Anderson GP, Bel E, Brusselle G, Cullinan P, Custovic A, Ducharme FM, Fahy JV et al. 2018. After asthma: Redefining airways diseases. Lancet. 391(10118):350-400.

18. Michie S, Richardson M, Johnston M, Abraham C, Francis J, Hardeman W, Eccles MP, Cane J, Wood CE. 2013. The behavior change technique taxonomy (v1) of 93 hierarchically clustered techniques: Building an international consensus for the reporting of behavior change interventions. Annals of behavioral medicine : a publication of the Society of Behavioral Medicine. 46(1):81-95.

19. Higgins JPT, Altman DG, Gotzsche PC, Juni P, Moher D, Oxman AD, Savovic J, Schulz KF, Weeks L, Sterne JAC et al. 2011. The cochrane collaboration's tool for assessing risk of bias in randomised trials. Bmj-Brit Med J. 343.

20. Schünemann HJ, Higgins JP, Vist GE, Glasziou P, Akl EA, Skoetz N, Guyatt GH. 2020. Cochrane handbook for systematic reviews of interventions version 6.1 In: Higgins JPT TJ, Chandler J, Cumpston M, Li T, Page MJ, Welch VA, editor. Chapter 14: Completing 'summary of findings' tables and grading the certainty of the evidence Cochrane. p. 375-402.

21. Baren JM, Boudreaux ED, Brenner BE, Cydulka RK, Rowe BH, Clark S, Camargo CA. 2006. Randomized controlled trial of emergency department interventions to improve primary care follow-up for patients with acute asthma. Chest. 129(2):257-265.

22. Canino G, Shrout PE, Vila D, Ramirez R, Rand C. 2016. Effectiveness of a multi-level asthma intervention in increasing controller medication use: A randomized control trial. Journal of Asthma. 53(3):301-310.

23. Chan AH, Stewart AW, Harrison J, Camargo CA, Jr., Black PN, Mitchell EA. 2015. The effect of an electronic monitoring device with audiovisual reminder function on adherence to inhaled corticosteroids and school attendance in children with asthma: A randomised controlled trial. The Lancet Respiratory medicine. $3(3): 210-219$. 
24. Chatkin JM, Blanco DC, Scaglia N, Wagner MB, Fritscher CC. 2006. Impact of a low-cost and simple intervention in enhancing treatment adherence in a brazilian asthma sample. Journal of Asthma. 43(4):263266.

25. Guendelman S, Meade K, Benson M, Chen YQ, Samuels S. 2002. Improving asthma outcomes and selfmanagement behaviors of inner-city children - a randomized trial of the health buddy interactive device and an asthma diary. Archives of Pediatrics \& Adolescent Medicine. 156(2):114-120.

26. Gustafson D, Wise M, Bhattacharya A, Pulvermacher A, Shanovich K, Phillips B, Lehman E, Chinchilli V, Hawkins R, Kim J-S. 2012. The effects of combining web-based ehealth with telephone nurse case management for pediatric asthma control: A randomized controlled trial. Journal of Medical Internet Research. 14(4):41-59.

27. Hederos CA, Janson S, Hedlin G. 2005. Group discussions with parents have long-term positive effects on the management of asthma with good cost-benefit. Acta Paediatrica. 94(5):602-608.

28. Mosnaim G, Li H, Martin M, Richardson D, Belice PJ, Avery E, Ryan N, Bender B, Powell L. 2013. The impact of peer support and mp3 messaging on adherence to inhaled corticosteroids in minority adolescents with asthma: A randomized, controlled trial. Journal of Allergy and Clinical Immunology: In Practice. $1(5): 485-493$.

29. Stergachis A, Gardner JS, Anderson MT, Sullivan SD. 2002. Improving pediatric asthma outcomes in the community setting: Does pharmaceutical care make a difference? Journal of the American Pharmaceutical Association (Washington,DC : 1996). 42(5):743-752.

30. van Es SM, Nagelkerke AF, Colland VT, Scholten R, Bouter LM. 2001. An intervention programme using the ase-model aimed at enhancing adherence in adolescents with asthma. Patient Education and Counseling. 44(3):193-203.

31. Wiecha JM, Adams WG, Rybin D, Rizzodepaoli M, Keller J, Clay JM. 2015. Evaluation of a web-based asthma self-management system: A randomised controlled pilot trial. BMC pulmonary medicine. 15:17.

32. Garrett J, Fenwick JM, Taylor G, Mitchell E, Stewart J, Rea H. 1994. Prospective controlled evaluation of the effect of a community-based asthma education center in a multiracial working-class neighborhood. Thorax. 49(10):976-983.

33. Burgess SW, Sly PD, Devadason SG. 2010. Providing feedback on adherence increases use of preventive medication by asthmatic children. Journal of Asthma. 47(2):198-201.

34. Julious SA, Horspool MJ, Davis S, Bradburn M, Norman P, Shephard N, Cooper CL, Smithson WH, Boote J, Elphick H et al. 2016. Pleasant: Preventing and lessening exacerbations of asthma in school-age children associated with a new term - a cluster randomised controlled trial and economic evaluation. Health technology assessment. 20(93):1-154.

35. Jan RL, Wang JY, Huang MC, Tseng SM, Su HJ, Liu LF. 2007. An internet-based interactive telemonitoring system for improving childhood asthma outcomes in taiwan. Telemedicine Journal and e-Health. 13(3):257-268.

36. Morton RW, Elphick HE, Rigby AS, Daw WJ, King DA, Smith LJ, Everard ML. 2017. Staar: A randomised controlled trial of electronic adherence monitoring with reminder alarms and feedback to improve clinical outcomes for children with asthma. Thorax. 72(4):347-354.

37. Vasbinder EC, Goossens LM, Rutten-van Molken MP, de Winter BC, van Dijk L, Vulto AG, Blankman EI, Dahhan N, Veenstra-van Schie MT, Versteegh FG et al. 2016. E-monitoring of asthma therapy to improve compliance in children (e-matic): A randomised controlled trial. Thorax. 48(3):758-767.

38. Teach SJ, Crain EF, Quint DM, Hylan ML, Joseph JG. 2006. Improved asthma outcomes in a highmorbidity pediatric population: Results of an emergency department-based randomized clinical trial. Archives 
of Pediatrics \& Adolescent Medicine. 160(5):535-541.

39. Kenyon CC, Gruschow SM, Quarshie WO, Griffis H, Leach MC, Zorc JJ, Bryant-Stephens TC, Miller VA, Feudtner C. 2019. Controller adherence following hospital discharge in high risk children: A pilot randomized trial of text message reminders. The Journal of asthma : official journal of the Association for the Care of Asthma. 56(1):95-103.

40. Kosse RC, Bouvy ML, de Vries TW, Koster ES. 2019. Effect of a mhealth intervention on adherence in adolescents with asthma: A randomized controlled trial. Respiratory medicine. 149:45-51.

41. Koumpagioti D, Boutopoulou B, Priftis KN, Douros K. 2020. Effectiveness of an educational program for children and their families on asthma control treatment adherence. Journal of Asthma. 57(5):567-573.

42. Davis SA, Carpenter D, Lee C, Garcia N, Reuland DS, Tudor G, Loughlin CE, Sleath B. 2019. Effect of an asthma question prompt list and video intervention on adolescents' medication adherence 12 months later. The Annals of pharmacotherapy. 53(7):683-689.

43. Ljungberg H, Carleborg A, Gerber H, Öfverström C, Wolodarski J, Menshi F, Engdahl M, Eduards M, Nordlund B. 2019. Clinical effect on uncontrolled asthma using a novel digital automated self-management solution: A physician-blinded randomised controlled crossover trial. Eur Respir J. 54(5).

44. Lv S, Ye X, Wang Z, Xia W, Qi Y, Wang W, Chen Y, Cai X, Qian X. 2019. A randomized controlled trial of a mobile application-assisted nurse-led model used to improve treatment outcomes in children with asthma. Journal of advanced nursing. 75(11):3058-3067.

45. Bresolini DSR, Queiroz M, Gaspar GR, Reis LD, Araujo A, Lasmar L. 2020. Use of home visits in pediatric severe asthma: Randomized controlled trial. Revista da Escola de Enfermagem da U S P. 54:e003538.

46. Hederos CA, Janson S, Hedlin G. 2005. Group discussions with parents have long-term positive effects on the management of asthma with good cost-benefit. Acta paediatrica. 94(5):602-608.

47. Gustafson D, M W, A B, A P, K S, B P, E L, V C, R H, J K. 2012. The effects of combining web-based ehealth with telephone nurse case management for pediatric asthma control: A randomized controlled trial. Journal of medical Internet research. 14(4):e101.

48. Lycett H. 2017. Behavioural science foundations for effective digital interventions: A systematic review. Paper presented at: European Society for Patient Adherence, COMpliance, and Persistence ESPACOMP. Budapest.

49. Horne R, Cooper V, Wileman V, Chan A. 2019. Supporting adherence to medicines for long-term conditions: A perceptions and practicalities approach based on an extended common-sense model. European Psychologist. 24(1):82-96.

50. Chapman SCE, Horne R, Eade R, Balestrini S, Rush J, Sisodiya SM. 2015. Applying a perceptions and practicalities approach to understanding nonadherence to antiepileptic drugs. Epilepsia. 56(9):1398-1407.

51. Mes MA, Katzer CB, Chan AHY, Wileman V, Taylor SJC, Horne R. 2018. Pharmacists and medication adherence in asthma: A systematic review and meta-analysis. Eur Respir J. 52(2).

52. Yilmaz O, Eroglu N, Ozalp D, Yuksel H. 2012. Beliefs about medications in asthmatic children presenting to emergency department and their parents. The Journal of asthma : official journal of the Association for the Care of Asthma. 49(3):282-287.

53. Conn KM, Halterman JS, Fisher SG, Yoos HL, Chin NP, Szilagyi PG. 2005. Parental beliefs about medications and medication adherence among urban children with asthma. Ambul Pediatr. 5(5):306-310.

54. Klok T, Kaptein AA, Duiverman EJ, Brand PL. 2015. Long-term adherence to inhaled corticosteroids in children with asthma: Observational study. Respiratory medicine. 109(9):1114-1119. 
55. Horne R, Chapman SCE, Parham R, Freemantle N, Forbes A, Cooper V. 2013. Understanding patients' adherence-related beliefs about medicines prescribed for long-term conditions: A meta-analytic review of the necessity-concerns framework. Plos One. 8(12).

56. Foot H, La Caze A, Gujral G, Cottrell N. 2016. The necessity-concerns framework predicts adherence to medication in multiple illness conditions: A meta-analysis. Patient Educ Couns. 99(5):706-717.

57. Murphy A, Proeschal A, Brightling C, Wardlaw A, Pavord I, Bradding P, Green R. 2012. The relationship between clinical outcomes and medication adherence in difficult-to-control asthma. Thorax. 67(8):751-753.

58. Turpin DL. 2005. Consort and quorom guidelines for reporting randomized clinical trials and systematic reviews. Am J Orthod Dentofacial Orthop. 128(6):681-685; discussion 686.

59. Looijmans-van den Akker I, van Luijn K, Verheij T. 2016. Overdiagnosis of asthma in children in primary care: A retrospective analysis. Br J Gen Pract. 66(644):e152-157.

60. Pearce CJ, Fleming L. 2018. Adherence to medication in children and adolescents with asthma: Methods for monitoring and intervention. Expert Rev Clin Immunol.

\section{Hosted file}

Table 1 Main extraction table.docx available at https://authorea.com/users/439643/articles/ 540525-interventions-to-improve-adherence-in-children-with-asthma-a-systematic-review

\section{Hosted file}

Table 2 adherence outcome results.docx available at https://authorea.com/users/439643/ articles/540525-interventions-to-improve-adherence-in-children-with-asthma-a-systematicreview

\section{Hosted file}

Table 3 Study reliability.docx available at https://authorea.com/users/439643/articles/ 540525-interventions-to-improve-adherence-in-children-with-asthma-a-systematic-review

\section{Hosted file}

Table 4 PAPA and reliability.docx available at https://authorea.com/users/439643/articles/ 540525-interventions-to-improve-adherence-in-children-with-asthma-a-systematic-review

\section{Hosted file}

Table 5 BCT examples.docx available at https://authorea.com/users/439643/articles/540525interventions-to-improve-adherence-in-children-with-asthma-a-systematic-review 


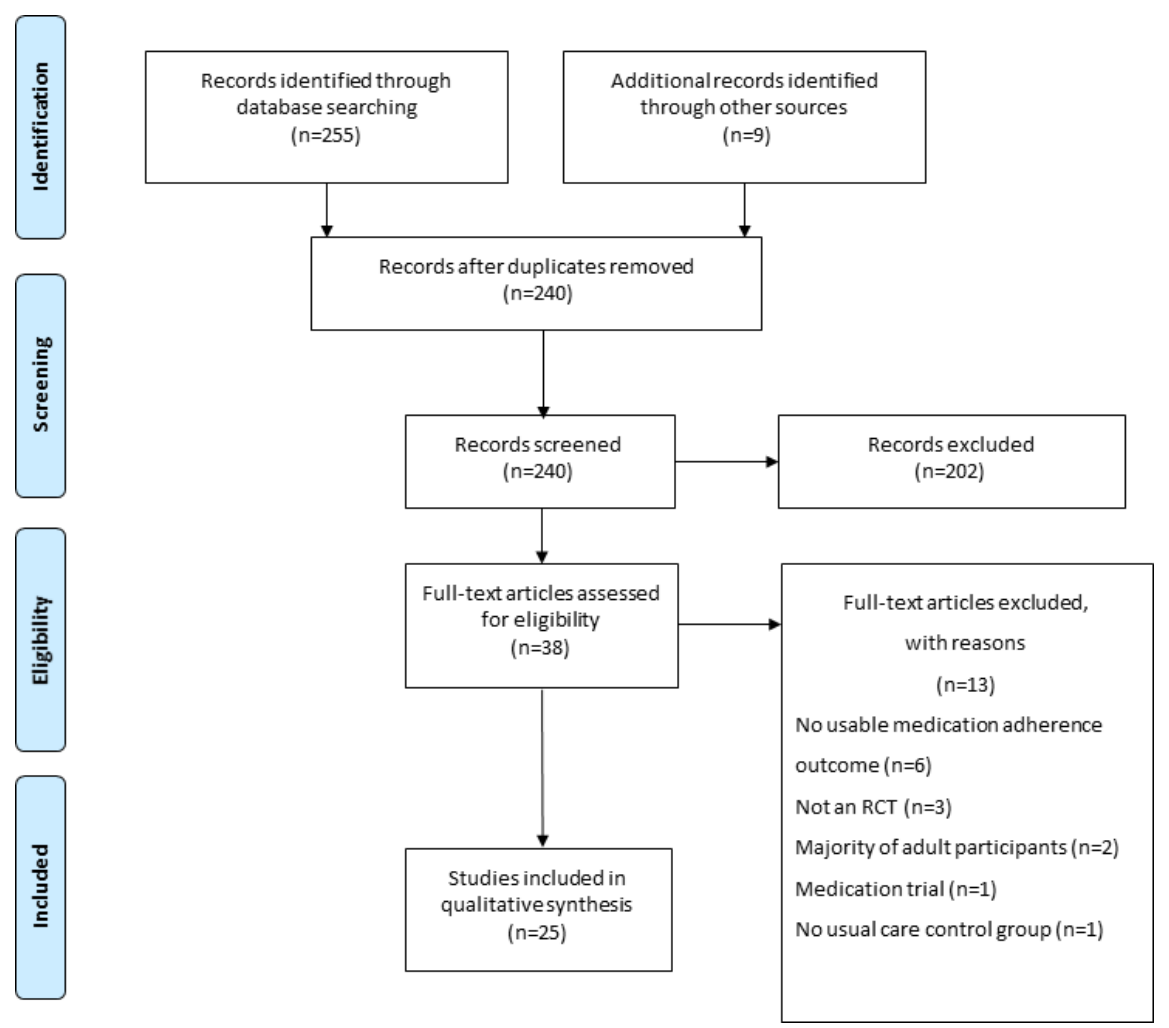




\begin{tabular}{|c|c|c|c|c|c|c|}
\hline & 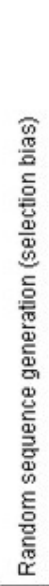 & 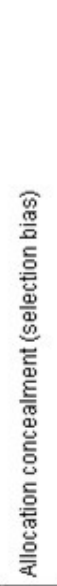 & 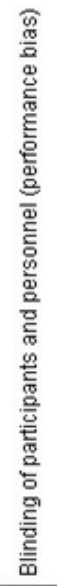 & 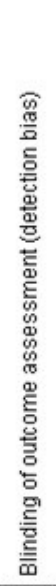 & 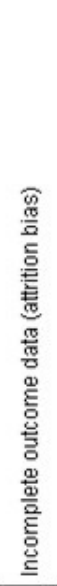 & 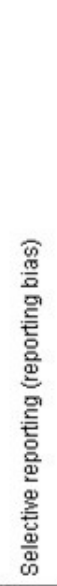 \\
\hline Baren 2006 & $\odot$ & $\odot$ & $(-$ & (†) & $\odot$ & ๑ \\
\hline Burgess 2010 & $?$ & $?$ & ? & + & $\odot$ & $\odot$ \\
\hline Canino 2016 & $\odot$ & $?$ & ○ & $\theta$ & $\odot$ & $\odot$ \\
\hline Chan 2015 & $\odot$ & $(+$ & $\odot$ & $\odot$ & $\odot$ & $\odot$ \\
\hline Chatkin 2009 & $\odot$ & $\odot$ & ๑ & $\odot$ & $?$ & $\odot$ \\
\hline Garrett 1994 & ? & ? & ○ & $?$ & ○ & $\odot$ \\
\hline Guendelman 2002 & $?$ & ○ & ○ & - & $?$ & $\odot$ \\
\hline Gustafson 2012 & ๑ & $\odot$ & ○ & $\odot$ & ○ & $\odot$ \\
\hline Hederos 2005 & O & $\theta$ & P & $\odot$ & $\odot$ & $\odot$ \\
\hline Jan 2007 & $?$ & O & $\odot$ & $?$ & 0 & $\odot$ \\
\hline Julious 2016 & $\odot$ & $\odot$ & $\odot$ & $\odot$ & $?$ & $\odot$ \\
\hline Morton 2017 & + & + & ○ & $\odot$ & $\theta$ & $\odot$ \\
\hline Mosnaim 2013 & 0 & $\theta$ & $\odot$ & $\odot$ & $\odot$ & $\odot$ \\
\hline Stergachis 2002 & + & + & $\theta$ & $\theta$ & $\theta$ & $\odot$ \\
\hline Teach 2006 & $\odot$ & (-) & † & $\odot$ & $?$ & $\odot$ \\
\hline vanEs 2001 & $\odot$ & - & ○ & ○ & $?$ & $\odot$ \\
\hline Vasbinder 2016 & $\odot$ & $\odot$ & $\theta$ & $\odot$ & $\theta$ & $\odot$ \\
\hline Wiecha 2015 & $?$ & $?$ & $?$ & (-) & - & 0 \\
\hline
\end{tabular}

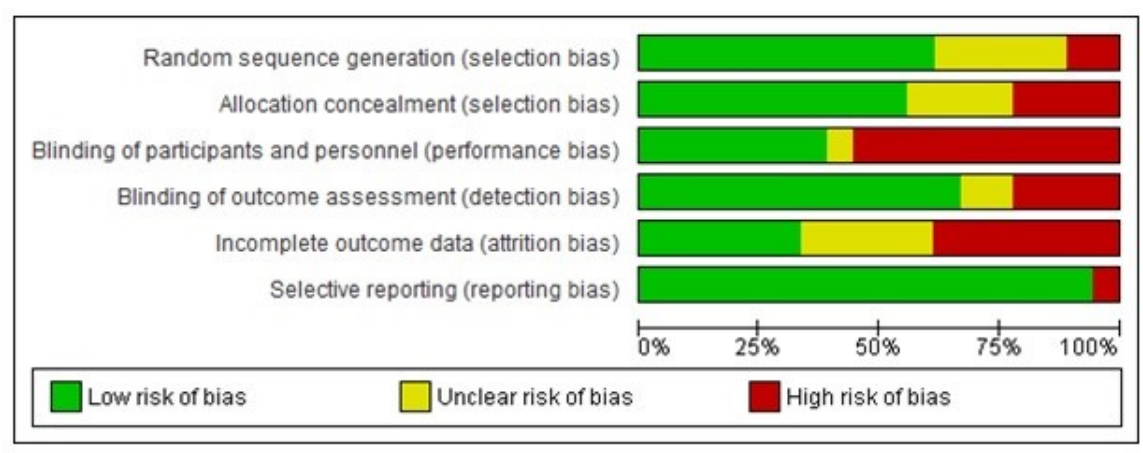




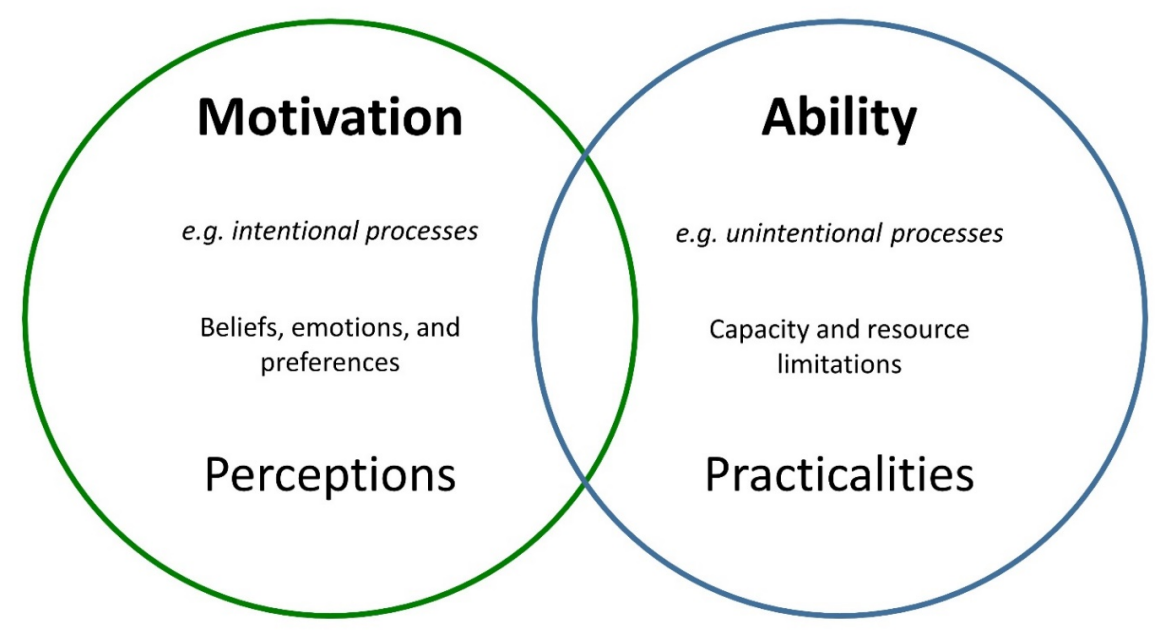

